\title{
Behaviour of protein carbonyl groups in juvenile myocardial infarction
}

\author{
Gregorio Caimi*, Baldassare Canino, Egle Incalcaterra, Eleonora Ferrera, Maria Montana \\ and Rosalia Lo Presti \\ Dipartimento di Medicina Interna e Specialistica, Università di Palermo, Italy
}

\begin{abstract}
Acute myocardial infarction (AMI) is accompanied by oxidative stress, and protein oxidation is among the consequences of oxidative stress. We examined the plasma concentration of protein carbonyl groups (PC), a marker of protein oxidation, in a group of young subjects with AMI (45 men and 5 women; mean age $40.4 \pm 4.8$ yrs). We found a significant increase of PC $(p<0.001)$ in comparison with normal controls. No difference was observed between patients with AMI characterized by elevated ST segment and those without elevation of ST segment. There was no correlation between the ejection fraction and PC in the whole group nor in the subgroups of STEMI and non-STEMI patients. Subdividing the whole group of AMI patients according to the number of risk factors and the number of stenosed coronary vessels, the difference in PC level was not statistically significant among the subgroups. This study showed an increased protein oxidation in young subjects with recent AMI. Further investigation is needed to ascertain whether this can be a target of therapeutic intervention.
\end{abstract}

Keywords: Juvenile coronary heart disease, oxidative stress, protein oxidation, cardiovascular risk factors

\section{Introduction}

Acute myocardial infarction (AMI) is associated with increased synthesis of reactive oxygen/nitrogen species (RONS) and the imbalance between RONS production and antioxidant systems (enzymatic and non-enzymatic) leads to oxidative stress.

Up to now several are the reports concerning lipid peroxidation (LP) in AMI. An increase in LP was found in AMI patients [12, 21, 26], with a progressive increase in the 7 days following the acute event [21]. The LP increase was more evident in AMI complicated by cardiogenic shock [22]. LeLeiko et al. [14] showed that F2-isoprostane, a marker of LP, predicted 30-day cardiovascular events in acute coronary syndrome. Deepa et al. [6] found a LP increase in diabetic and non-diabetic AMI patients compared to normal controls. Other authors [7] noted that in AMI patients with type 2 diabetes mellitus the malonildialdheyde level was correlated with the glycometabolic parameters. Bagatini et al. [1] observed a significant correlation between LP and troponin I in AMI patients. We have previously studied oxidative stress in juvenile AMI, defined as AMI in patients aged $<46$ years, observing a decrease in total antioxidant status and an increase in lipid peroxidation (LP), both still present 12 months after the acute event [17].

\footnotetext{
${ }^{*}$ Corresponding author: Prof. Gregorio Caimi, Dipartimento di Medicina Interna e Specialistica, Università di Palermo, Via del Vespro, 129-90127 Palermo, Italy. Tel.: +39 91655 4406; Fax: +39 91655 4535; E-mail: gregorio.caimi@ unipa.it.
} 
Protein oxidation is among the effects of oxidative stress. When RONS attack aminoacids, protein carbonyl groups (PC) are produced. They are constituted by oxidation of the side chains of lysine, proline, arginine and threonine residues. Up to now the PC measurement is the most employed measure of protein oxidation [5, 9].

Few are the data regarding the behaviour of protein oxidation in coronary heart diseases. A protein oxidation increase, expressed as a high level of advanced oxidation protein products (AOPP), was found in coronary artery disease and was related to the severity score of coronary lesions [13]. Serum protein carbonyls were higher in patients with coronary artery disease and correlated with the obstructive vessel number [23]. Some authors observed a protein oxidation increase in patients with AMI characterized by elevated ST segment (STEMI) and not in those without elevation of ST segment (non-STEMI) [25]. This difference was not observed by others, who examined PC in 3 different groups of patients, with respectively unstable angina, non-STEMI and STEMI [24]. In another report [8] the increase of protein oxidation observed in STEMI patients was correlated with pain to hospital time and was associated with higher incidence of adverse cardiac events. Bagatini et al. [1] observed, in comparison with healthy controls, an increase of PC levels in AMI patients but also in a control group with cardiovascular risk factors (smoking, hypertension, family history of heart disease). Other authors [2] observed an increase of AOPP in a small group of AMI patients at the hospital admission, and a trend towards normal levels after 1 and 6 months.

We previously described the behaviour of protein oxidation, expressed as PC levels, in patients with mild essential hypertension [4] and in trained subjects [16]. The aim of the present study was to examine protein oxidation, expressed as PC, in young subjects with recent AMI. This study is a part of the scientific project identified as "Sicilian Study on Juvenile Myocardial Infarction". In these patients we have recently described the possible role of genetic polymorphisms as factors predisposing to AMI at young age [11].

\section{Subjects and methods}

In this research we examined 50 patients ( 45 men and 5 women) with recent AMI, aged $<46$ years. The mean age was $40.4 \pm 4.8$ years. The time interval between AMI onset and the examination was $13 \pm 7$ days. In each patient we investigated the presence of the main cardiovascular risk factors, including arterial hypertension, hypercholesterolemia, diabetes mellitus, family history of coronary artery disease and current smoking habits. Arterial hypertension was defined as a systolic blood pressure $>140 \mathrm{mmHg}$ and/or a diastolic blood pressure $>90 \mathrm{mmHg}$ and/or use of anti-hypertensive drugs. Diabetes was defined as a fasting blood glucose level $>125 \mathrm{mg} / \mathrm{dl}$ and/or use of hypoglycemic agents. Hypercholesterolemia was defined as a total plasma cholesterol level $>220 \mathrm{mg} / \mathrm{dl}$ and/or the use of lipid lowering drugs. Family history consisted in any first-grade relative with clinical manifestations of coronary artery disease at age $<55$ years. According to the number of risk factors the patients were subdivided into 3 groups: 14 of them had 0 to 1 risk factor, 21 had 2 risk factors and 15 had 3 to 5 risk factors. Thirty-one patients had STEMI, 19 had non-STEMI. In each patient the ejection fraction (EF) was evaluated by echocardiography. The mean EF in the whole group was $54.7 \pm 6.6 \%$; only 3 subjects had EF $<45 \%$. There was no significant difference in EF between STEMI and non-STEMI patients. Coronary angiography was performed only in 44 patients. In the other cases the patient refused his consent or the angiography was not performed due to the long distance between the hospital in which AMI was diagnosed and the angiography unit. The 44 subjects in which coronary angiography was performed were subdivided into 3 groups on the basis of the extent of coronary lesions: 9 patients did not show any significant coronary stenosis, 22 patients 
had a single-vessel disease (defined as a $>70 \%$ stenosis in one coronary artery), and 13 patients had a multi-vessel disease, that is a $>70 \%$ stenosis in at least two coronary vessels. No patient had previous manifestations of coronary artery disease or other comorbidities.

The control group included 42 subjects ( 35 men and 7 women; mean age $38.6 \pm 5.3$ yrs) without signs of acute or chronic vascular diseases (history, physical examination, laboratory and instrumental tests).

The study was approved by the Ethical Committee and each subjects gave informed consent.

Blood samples were collected by venous puncture from the antecubital vein and immediately transferred to glass tube anticoagulated with EDTA-K3; the parameter evaluated was protein oxidation.

\subsection{Protein oxidation}

PC were measured by an enzyme-linked immunosorbent assay (ELISA) kit (BioCell PC test kit, Enzo Life Sciences AG, Switzerland). It uses the classic PC reagent 2,4-dinitrophenyl-hydrazine (DNP), which reacts with the PC forming a stable hydrazone product.

In brief, plasma samples were incubated with DNP, and then plasma proteins were non-specifically adsorbed to the wells of an ELISA plate. Unconjugated DNP and non-protein constituents were washed away. The adsorbed proteins were probed with a biotinylated anti-DNP antibody, followed by streptavidinlinked horseradish peroxidase. A chromatin reagent was added, and the reaction was stopped by adding an acid solution. Absorbance for each well was measured at $450 \mathrm{~nm}$ and related to a standard curve prepared for serum albumin, containing increasing proportions of hypochlorous acid-oxidized protein, calibrated colorimetrically.

Total protein concentration in plasma samples was evaluated by the method of Lowry et al. [18].

\section{Statistical analysis}

Data were expressed as means $\pm \mathrm{SD}$; the difference between control subjects and young AMI patients was evaluated according to the Student $t$ test for unpaired data. The statistical difference between control subjects and AMI patients subdivided according to the number of cardiovascular risk factors and to the number of stenosed coronary vessels was evaluated according to the one-way analysis of variance (ANOVA) model; then the Bonferroni multiple $t$ test was performed to compare every pair of subgroups. The correlation between EF and PC was evaluated by linear regression.

\section{Results}

In young AMI patients $\mathrm{PC}$ were significantly increased in comparison with control subjects $(\mathrm{C}=0.422 \pm 0.129 \mathrm{nmol} / \mathrm{mg}$ prot; AMI patients $=0.605 \pm 0.179 \mathrm{nmol} / \mathrm{mg}$ prot; $p<0.001)$. No significant difference in PC was observed between STEMI (PC $=0.593 \pm 0.189 \mathrm{nmol} / \mathrm{mg}$ prot $)$ and non-STEMI ( $\mathrm{PC}=0.594 \pm 0.134 \mathrm{nmol} / \mathrm{mg}$ prot). Subdividing young AMI patients according to the number of risk factors, no significant difference was observed between the three subgroups (Table 1); similarly, subdividing AMI patients according to the number of stenosed coronary vessels, there was no difference among the three subgroups (Table 1). There was no correlation between EF and PC in the whole group nor in the subgroups of STEMI and non-STEMI patients. There was no significant difference in PC when the main coronary stenosis regarded the left anterior descending artery 
Table 1

Means \pm S.D. of protein carbonyl groups (PC) in control subjects and in AMI patients, subdivided according to the number of risk factors (A) or to the number of stenosed coronary vessels (B)

\begin{tabular}{|c|c|c|c|c|c|}
\hline A & Control subjects & $\begin{array}{l}\text { AMI 0-1 risk } \\
\text { factors }\end{array}$ & $\begin{array}{l}\text { AMI } 2 \text { risk } \\
\text { factors }\end{array}$ & $\begin{array}{l}\mathrm{AMI}>2 \text { risk } \\
\text { factors }\end{array}$ & $\mathrm{F}$ \\
\hline PC (nmol/mg prot) & $0.422 \pm 0.129$ & $0.581 \pm 0.165^{\#}$ & $0.593 \pm 0.192^{*}$ & $0.645 \pm 0.180^{*}$ & $10.6^{1}$ \\
\hline B & Control subjects & $\begin{array}{l}\text { AMI subjects } \\
\text { with no } \\
\text { coronary } \\
\text { lesions }\end{array}$ & $\begin{array}{l}\text { AMI subjects } \\
\text { with } 1 \\
\text { stenosed } \\
\text { vessel }\end{array}$ & $\begin{array}{l}\text { AMI subjects } \\
\text { with } 2 \text { or } 3 \\
\text { stenosed } \\
\text { vessels }\end{array}$ & $\mathrm{F}$ \\
\hline PC (nmol/mg prot) & $0.422 \pm 0.129$ & $0.659 \pm 0.182^{*}$ & $0.597 \pm 0.166^{*}$ & $0.575 \pm 0.175^{\S}$ & $10.8^{1}$ \\
\hline
\end{tabular}

${ }^{1} p<0.001$ (ANOVA); $p<0.05^{\#} p<0.01 * p<0.001$ vs. control subjects (Bonferroni's test).

$(\mathrm{PC}=0.626 \pm 0.182 \mathrm{nmol} / \mathrm{mg}$ prot $)$, the left circumflex artery $(\mathrm{PC}=0.501 \pm 0.142 \mathrm{nmol} / \mathrm{mg} \mathrm{prot})$ or the right coronary artery $(\mathrm{PC}=0.604 \pm 0.123 \mathrm{nmol} / \mathrm{mg}$ prot $)$.

\section{Conclusive considerations}

Young AMI patients showed an increase in protein oxidation and this increase was present both in STEMI and non-STEMI patients. The subdivision according to either the number of risk factors or the extent of coronary disease showed an opposite trend: PC level was in fact higher in patients with more risk factors and in those with less coronary lesions, although the differences between the AMI subgroups did not reach statistical significance.

Our results confirm the literature data about the increase of protein oxidation found in AMI patients not selected according to age [1,2, 8, 24, 25], as well as our previous report concerning the behaviour of lipid peroxidation in young AMI patients [17]. These data do not confirm the significant correlation between protein oxidation and the severity of coronary disease which was observed by other authors [23].

There are some reports regarding short-term antioxidant treatments able to reduce lipid peroxidation after AMI and reperfusion [3, 29]; moreover, antioxidants seem to have a cardioprotective action in patients with chronic coronary artery disease [19]. As regards protein oxidation, there are data about the carbonyl scavenger activity played by some molecules [10,15, 20]; in particular L-arginine significantly reduced the level of protein oxidation in ischemic heart disease [27, 28].

In conclusion, protein oxidation is a marker of the oxidative stress observed in young patients with recent AMI. Oxidative stress is involved in atherogenesis, therefore its correction might reduce the progression of the coronary atherosclerotic lesions and improve prognosis in these patients, but its effective usefulness must be demonstrated by controlled long-term clinical studies.

\section{Acknowledgments}

The authors comply with the Ethical Guidelines for Publication in Clinical Hemorheology and Microcirculation as published on the IOS Press website and in Volume 44, 2010, pp. 1-2 of this journal. 


\section{References}

[1] M.D. Bagatini, C.C. Martins, V. Battisti, D. Gasparetto, C.S. da Rosa, R.M. Spanavello, M. Ahmed, R. Schmatz, M.R.C. Schetinger and V.M. Morsch, Oxidative stress versus antioxidant defenses in patients with acute myocardial infarction, Heart and Vessels 26 (2011), 55-63.

[2] A. Barsotti, P. Fabbi, M. Fedele, S. Garibaldi, M. Balbi, G.P. Bezante, D. Risso, F. Indiveri, G. Ghigliotti and C. Brunelli, Role of advanced oxidation protein products and Thiol ratio in patients with acute coronary syndromes, Clinical Biochemistry (2011), doi 10.1016/j.clinbiochem.2011.03.134

[3] P. Bhakuni, M. Chandra and M.K. Misra, Effect of ascorbic acid supplementation on certain oxidative stress parameters in the post reperfusion patients of myocardial infarction, Molecular and Cellular Biochemistry 290 (2006), 153-158.

[4] G. Caimi, G. Mulè, E. Hopps, C. Carollo and R. Lo Presti, Protein oxidation in mild essential hypertension, Clinical Hemorheology and Microcirculation 2012 Jan 3 [epub ahead of print].

[5] M. Chevion, E. Berenshtein and E.R. Stadtman, Human studies related to protein oxidation: Protein carbonyl content as a marker of damage, Free Radical Research 33(Suppl) (2000), S99-S108.

[6] M. Deepa, P. Pasupathi, K.B. Sankar, P. Rani and S.P. Kumar, Free radicals and antioxidant status in acute myocardial infarction patients with and without diabetes mellitus, Bangladesh Medical Research Council Bulletin 35 (2009), 95-100.

[7] H. El-Mesallamy, N. Hamdy, S. Suwailem and S. Mostafa, Oxidative stress and platelet activation: Markers of myocardial infarction in type 2 diabetes mellitus, Angiology 61 (2010), 14-18.

[8] Y. Feng, C. Shen, G. Ma, J. Wang, Z. Chen, Q. Dai, C. Yang, Q. Fu, G. Shang and Y. Guan, Prolonged pain to hospital time is associated with increased plasma advanced oxidation protein products and poor prognosis in patients with percutaneous coronary intervention for ST-elevation myocardial infarction, Heart and Vessels 25 (2010), 374-378.

[9] M. Flint Beal, Oxidatively modified proteins in aging and disease, Free Radical Biology and Medicine 32 (2002), 797-803.

[10] S. Galvani, C. Coatrieux, M. Elbaz, M.H. Grazide, J.C. Thiers, A. Parini, K. Uchida, N. Kamar, L. Rostaing, M. Baltas, R. Salvayre and A. Negre-Salvayre, Carbonyl scavenger and antiatherogenic effects of hydrazine derivatives, Free Radical Biology and Medicine 45 (2008), 1457-1467.

[11] E. Incalcaterra, M. Caruso, C.R. Balistreri, G. Candore, R. Lo Presti, E. Hoffmann and G. Caimi, Role of genetic polymorphisms in myocardial infarction at young age, Clinical Hemorheology and Microcirculation 46 (2010), 291-298.

[12] K. Iqbal, M.A. Rauoof, M.M. Mir, N.A. Tramboo, J.A. Malik, B.A. Naikoo, M.A. Dar, S.R. Masoodi and A.R. Khan, Lipid peroxidation during acute coronary syndrome and its intensification at the time of myocardial ischemia reperfusion, American Journal of Cardiology 89 (2002), 334-337.

[13] H. Kaneda, J. Taguchi, K. Ogasawara, T. Aizawa and M. Ohno, Increased level of advanced oxidation protein products in patients with coronary artery disease, Atherosclerosis 162 (2002), 221-225.

[14] R.M. LeLeiko, C.S. Vaccari, S. Sola, N. Merchant, S.H. Nagamia, M. Thoenes and B.V. Khan, Usefulness of elevations in serum choline and free F2-Isoprostane to predict 30-day cardiovascular outcomes in patients with acute coronary syndrome, American Journal of Cardiology 104 (2009), 638-643.

[15] G. Li, T. Tang, M. Peng, H. He and D. Yin, Direct reaction of taurine with malondialdehyde: Evidence for taurine as a scavenger of reactive carbonyl species, Redox Reports 15 (2010), 268-274.

[16] R. Lo Presti, B. Canino, M. Montana, V. Calandrino and G. Caimi, Protein carbonyl groups in trained subjects, Clinical Hemorheology and Microcirculation 2012 Jan 3 [epub ahead of print].

[17] R. Lo Presti, A. Catania, T. D'Amico, M. Montana, M. Caruso and G. Caimi, Oxidative stress in young subjects with acute myocardial infarction: Evaluation at the initial stage and after 12 months, Clinical and Applied Thrombosis and Hemostasis 14 (2008), 421-427.

[18] O.H. Lowry, N.J. Rosebrough, A.L. Farr and T.D. Randall, Protein measurement with the Folin phenol reagent, The Journal of Biological Chemistry 193 (1951), 265-275.

[19] K. Magyar, R. Halmosi, A. Palfi, G. Feher, L. Czopf, A. Fulop, I. Battyany, B. Sumegi, K. Toth and E. Szabados, Cardioprotection by resveratrol: A human clinical trial in patients with stable coronary artery disease, Clinical Hemorheology and Microcirculation 2012 Jan 3 [epub ahead of print].

[20] A. Negre-Salvayre, C. Coatrieux, C. Ingueneau and R. Salvayre, Advanced lipid peroxidation end products in oxidative damage to proteins. Potential role in diseases and therapeutic prospects for the inhibitors, British Journal of Pharmacology 153 (2008), 6-20. 
[21] V. Nikolic-Heitzler, F. Rabuzin, F. Tatzber, N. Vrkic, N. Bulj, S. Borovic, W. Wonisch, B.M. Sunko and N. Zarkovic, Persistent oxidative stress after myocardial infarction treated by percutaneous coronary intervention, Experimental Medicine 210 (2006), 247-255.

[22] S. Senthil, R.M. Veerappan, M. Ramakrishna Rao and K.V. Pugalendi, Oxidative stress and antioxidants in patients with cardiogenic shock complicating acute myocardial infarction, Clinica Chimica Acta 348 (2004), 131-137.

[23] Z. Serdar, K. Aslan, M. Dirican, E. Sarandol, D. Yesilbursa and A. Serdar, Lipid and protein oxidation and antioxidant status in patients with angiographically proven coronary artery disease, Clinical Biochemistry 39 (2006), 794-803.

[24] Z. Serdar, A. Serdar, A. Altin, U. Eryilmaz and S. Albayrak, The relation between oxidant and antioxidant parameters and severità of acute coronary syndromes, Acta Cardiologica 62 (2007), 373-380.

[25] M. Skvarilova, A. Bulava, D. Stejskal, S. Adamovska and J. Bartek, Increased level of advanced oxidation products (AOPP) as a marker of oxidative stress in patients with acute coronary syndrome, Biomedical Papers 149 (2005), 83-87.

[26] R.H. Surekha, B.B.M.V. Srikanth, P. Jharna, R.V. Ramachandra, R.V. Daysagar and A. Jyothy, Oxidative stress and total antioxidant status in myocardial infarction, Singapore Medical Journal 48 (2007), 137-142.

[27] P. Tripathi, M. Chandra and M.K. Misra, Oral administration of L-arginine in patients with angina or following myocardial infarction may be protective by increasing plasma superoxide dismutase and total thiols with reduction in serum cholesterol and xanthine oxidase, Oxidative Medicine and Cellular Longevity 2 (2009), 231-237.

[28] P. Tripathi and M.K. Misra, Therapeutic role of L-arginine on free radical scavenging system in ischemic heart diseases, Indian Journal of Biochemistry and Biophysiology 46 (2009), 498-502.

[29] D. Yesilbursa, A. Serdar, T. Senturk, Z. Serdar, S. Sag and J. Cordan, Effect of N-acetylcysteine on oxidative stress and ventricular function in patients with myocardial infarction, Heart and Vessels 21 (2006), 33-37. 